\title{
PERANCANGAN VIDEOGRAFI SEBAGAI MEDIA PROMOSI BATIK KHAS SUBANG YANG DIPRODUKSI OLEH BATIK GANASAN
}

\author{
${\text { Ogi Sugiantor), Nichi Hana Karlina }{ }^{2)} \text {, Sophia Purbasari }}^{\text {3) }}$ \\ Fakultas Komunikasi dan Desain \\ Universitas Informatika dan Bisnis Indonesia \\ Email: ogisugianto@gmail.com, nichi.hana@unibi.ac.id,sophia041@unibi.ac.id
}

\begin{abstract}
Abstrak
Sejak batik dikukuhkan oleh UNESCO (United Nations Educational, Scientific, and Cultural Organization) sebagai Warisan Kemanusiaan untuk Budaya Lisan dan Non-Bendawi sejak oktober 2009, perkembangan batik di Indonesia berkembang secara pesat, banyak daerah di Indonesia yang memiliki dan mengembangkan batiknya sesuai identitas kedaerahan, termasuk di Kabupaten Subang yang sudah berkembang dan telah muncul beragam industri Batik khas Subang. Salah satu industri Batik khas Subang yang terkenal adalah Ganasan Batik. Di Ganasan Batik, dibuat kain batik dengan motif yang beragam dan menggambarkan kekayaan alam dan tradisi di Kabupaten Subang, seperti motif nanas, sisingaan dan bejana purba. Laporan perancangan Tugas Akhir mengenai Batik khas Subang ini memiliki rumusan masalah, bagaimana media promosi yang efektif dan efisien untuk mempromosikan Batik khas Subang yang diproduksi Batik Ganasan. Tujuan dari perancangan Tugas Akhir ini adalah untuk mempromosikan batik khas Subang melalui media videografi dan target dari perancangan media promosi ini adalah usia dewasa awal yang aktif menggunakan media sosial.Penelitian ini menggunakan metode kualitatif, dengan teknik pengumpulan data primer yang berupa wawancara, observasi dan studi pustaka, dan data sekunder dengan menggunakan kuesioner sebagai media pengumpulan data. Berdasarkan analisa data yang dilakukan, diperoleh kesimpulan bahwa, industri Batik Ganasan telah melakukan upaya mempromosikan batik khas Subang degan cara direct selling, yaitu promosi secara langsung via media online berupa Whatsapp. Namun upaya tersebut belum efektif untuk mempromosikan batik khas Subang, terutama secara cakupan target promosi.
\end{abstract}

Kata Kunci: Motif Batik, Batik khas Subang, Batik Ganasan, Videografi.

\begin{abstract}
Since batik was established by UNESCOas a Masterpece of the Oral and Intangible Haritage of Humanity Culture since October 2009, the development of batik in Indonesia developed rapidly, many regions in Indonesia possessed and developed batik in accordance with regional identity, including in Subang Regency which has developed and has emerged a variety of typical Batik Subang industry. One of the famous batik industries in Subang is Batik Ganasan. In Ganasan Batik, batik cloth is made with diverse motifs and is full of natural wealth and traditions in Subang Regency, such as pineapple motifs, sisingaan and ancient vessels. This Final Project Design Report on Subang Batik has the formulation of the problem regarding effective and efficient promotional media for the work on typical Batik Subang that produces Batik Ganasan. The purpose of the design of this Final Project is to promote the unique batik of Subang through videography media and the target of designing this promotional media is the early adultage is actively using social media.This study uses qualitative methods, with primary data collection techniques in the form of interviews, observation and literature study, and secondary data using a questionnaire as a data collection medium. Based on the data analysis, it was concluded that the Batik Ganasan industry had made an effort to promote the typical batik of Subang by direct selling, namely direct promotion via online media in the form of whatsapp. However, these efforts have not been effective to promote batik typical of Subang, especially in terms of coverage of promotional targets.
\end{abstract}

Keyword: Batik motifs, Batik Subang, Batik Ganasan, Videography. 
1.

\section{PENDAHULUAN}

Batik adalah kerajinan yang telah menjadi bagian dari budaya Indonesia (khususnya Jawa) sejak dahulu, dan juga merupakan warisan budaya nusantara (Indonesia) yang mempunyai nilai dan perpaduan seni yang tinggi, sarat dengan makna filosofis dan simbol penuh makna yang memperlihatkan cara berpikir masyarakat pembuatnya. Asti M. dan Ambar B. Arini (2011: 1) menjelaskan, berdasarkan etimologi dan terminologinya, batikmerupakan rangkaian kata mbat dan tik. Mbat dalam bahasa Jawa dapat diartikansebagai ngembat atau melempar berkali-kali, sedangkan tik berasal dari kata titik.Sehingga, membatik artinya melempar titik berkali-kali pada kain.

Perkembangan batik saat ini mulai pesat, khususnya di daerah pulau Jawa. Saat ini batik diproduksi berdasarkan motif atau corak dari sesuatu daerah, seperti motif batik Tujuh Rupa yang berasal dari Pekalongan, motif batik Keraton Yogyakarta, motif batik Sogan Solo, motif batik Gentongan Madura, dan motif-motif khas daerah lainnya.

Motif batik sendiri adalah kerangka gambar yang mewujudukan batik secara keseluruhan. Sampai saat ini, motif batik yang ada di Indonesia dikelompokan menjadi 7 kelompok motif batik, di antaranya motif Batik Parang, Geometri, Banji, Tumbuhan Menjalar, Tumbuhan Air, Bunga, dan motif Batik Satwa dan Kehidupannya.

Perkembangan batik tidak hanya berkembang di wilayah Jawa tengah dan timur, seperti di kota Yogyakarta,Pekalongan dan Solo, Tetapi di Jawa Barat pun cukup mulai berkembang seperti batik dari Kota Cirebon, Cimahi, Bandung dan Kabupaten Subang. Batik yang berkembang di Kabupaten Subang memiliki ciri khas yang berbeda dengan wilayah lainnya, sebagian banyak motifnya terinspirasi dari kekayaan alam dan tradisi yang berkembang di wilayah Kabupaten Subang.

Motif batik khas Kabupaten Subang yang berkembang diantaranya motif ganas yang terinspirasi buah nanas, motif daun teh, motif sisingaan, motif kupu-kupu, motif pohon ki tambleg, motif bejana purba dan motif gedung wisma karya.Pada Januari 2016, batik Subang resmi masuk dalam Peraturan Daerah (Perda) Kabupaten Subang. Disahkan oleh bupati Subang saat itu, H. Ojang Sohandi S.STP., M.Si bersama ketua DPRD Kabupaten Subang Ir. Beni Rudiono. Dalam Perda tersebut dicantumkan, motif batik yang merupakan batik ciri khas Subang adalah batik Sisingaan, Nanas dan Bejana Purba (batik purba).

Sebagai warisan budaya yang memiliki potensi untuk terus dikembangkan, pemerintah Kabupaten Subang telah melakukan upaya sosialisasi kepada masyarakat terkait batik khas Subang tersebut, yaitu dengan ditetapkannya batik khas Subang (motif ganas) sebagai pakaian resmi batik sekolah dan Aparatur Sipil Negara yang wajib dipakai pada hari rabu.

Hasil dari sosialisasi tersebut, membuat batik khas Subang mulai dikenal oleh masyarakat. Berdasarkan hasil survei, tercatat 80,9\% atau 34 dari 42 responden, menyatakan masyarakat Subang mengetahui tentang batik tersebut, salah satunya batik nanas yang biasa dipakai ASN atau batik anak sekolah.

Banyak industri batik khas Subang yang berdada di Kabupaten Subang. Salah satunya adalah Ganasan Batik, yang berlokasi di daerah Binong, Kabupaten Subang. Industri batik ini mulai dirintis pada tahun 2010 silam. Di Ganasan Batik ini, di produksi beragam motif khas subang, salah satunya ketiga motif yang telah dimasukan kedalam perda Subang, yaitu Nanas, Sisingaan, dan Bejana purba.

Sembilan tahun merintis usaha batik, produk dari Batik Ganasan ternyata belum dikenal serta belum menarik minat khususnya masyarakat Kabupaten Subang. Dimana hanya sebagian pihak yang mengetahui dan membeli produk Batik Ganasan tersebut.

Menurut penuturan pemilik industri Batik Ganasan, Mulyana, hampir 90 persen yang membeli batik di Batik Ganasan berasal dari lingkungan instansi pemerintah atau Aparatur Sipil Negara (ASN) sedangkan masyarakat lokal skalanya pembeliannya masih kecil.

Faktor yang mempengaruhi kurang dikenalnya Batik Ganasan adalah belum gencarnya promosi yang dilakukan oleh pihak Batik Ganasan, dimana sejauh ini hanya melaukan promosi melalui galeri 
pameran serta direct sellingvia aplikasi ponsel seperti Whatsapp, sehingga cakupan promosi masih terbatas.

Faktor lain yang mempengaruhi belum diminatinya batik Ganasan adalah pengetahuan masyarakat tentang batik, dimana masyarakat masih membandingkan batik printing yang harganya lebih murah dengan batik tulis dan cap yang cennderung harganya mahal. Sehingga banyak konsumen yang mengurungkan niat untuk membeli produk Batik Ganasan.

Berdasarkan data diatas, maka dibutuhkan sebuah media promosi yang tepat untuk mengenalkan Batik Ganasan yang menggambarkan filosofi serta kualitas dari Batik Ganasan. Media utama yang akan penulis gunakan dalam perancangan ini yaitu bentuk video promosi yang akan di publikasikan ke media sosial. Menggunakan promosi video sebagai media utama karena saat ini era globalisasi dan transformasi sistem informasi yang semakin canggih, karenavideo ini akan di promosikan melalui media sosial yang saat sekarang ini menjadi trend dan kebutuhan, seperti facebook, instagram, twitter, youtube,dan yang lainya.

Media sosial memiliki cakupan yang umum dan luas, melalui media sosial penggunanya bisa dengan mudah beradaptasi, berbagi, dan berinteraksisosial dalam media online, lengkap dan dengan tampilan yang lebih menarik.Promosi dengan menggunakan media sosial juga dapat terkontrol dengan jelas, bisa mendapatkan data yang terukur dalam waktu sekejap mengenai jangkauan serta efektifitasnya.

\subsection{Rumusan Masalah}

Bagaimana membuat perancangan media promosi yang efektif dan efisien untuk mempromosikan batik khas Subang yang diproduksi oleh Batik Ganasan?

\subsection{Metode Penelitian}

Pada perancangan ini peneliti dalam membuat karya menggunakan metode riset atau penelitian dengan metodologi kualitatif. Metodologi kualitatif menurut Creswell mengemukakan definisi penelitian kualitatif sebagai suatu pendekatan atau penelusuran untuk mengeksplorasi dan memahami suatu gejala sentral. Untukmengerti gejala sentral tersebut peneliti mewawancarai peserta penelitian atau partisipan dengan mengajukan pertanyaan yang umum dan agak luas (2010:7).

Adapun alasan penelitian ini menggunakan metode kualitatif adalah karena dalam penelitian ini data yang dihasilkan berupa data deskriptif yang diperoleh dari datadata berupa tulisan, kata-kata dan dokumen yang berasal dari sumber atau informan yang diteliti dan dapat dipercaya.

\section{TINJAUAN PUSTAKA}

\subsection{Batik}

Batik di Indonesia merupakan suatu keseluruhan teknik, teknologi, serta pengembangan motif dan budaya yang terkait, yang oleh UNESCO (United Nations Educational, Scientific and Cultural Organization) ditetapkan sebagai Warisan Kemanusiaan untuk Budaya Lisan dan NonBendawi (Masterpece of the Oral and Intangible Haritage of Humanity) sejak oktober 2009. Berdasarkan etimologi dan terminologinya,batik merupakan rangkaian kata mbat dan tik. Mbat dalam bahasa Jawa dapat diartikan sebagai ngembat atau melempar berkali-kali, sedangkan tik berasal dari kata titik. Membatik artinya melempar titik berkalikali pada kain (Asti M. dan Ambar B. Arini, 2011:1).

\subsection{Videografi}

Arsyad (dalam Rusman dkk, 2012: 218) menyebutkan bahwa video merupakan serangkaian gambar gerak yang disertai suara yang membentuk satukesatuan yang dirangkai menjadi sebuah alur dengan pesan-pesan didalamnya untukketercapaian tujuan pembelajaran yang disimpan dengan proses penyimpanan pada mediapita atau disk. Semedhi (2011: 2) mengungkapkan ilmu videografi berarti ilmu yang mempelajari teknik pembuatan gambar dan suara untuk media massa yang memiliki peran penting dalam era informasi dan komunikasi saat ini.

\subsection{Promosi}


Volume 02 No. 02, November 2019

Promosi merupakan elemen bauran pemasaran yang berfokus pada upaya menginformasikan, membujuk, dan mengingatkan kembali konsumen akan produk dan merek perusahaan (Tjiptono, 2017: 387)

\section{METODE PENELITIAN}

\subsection{Batik Subang}

Batik Subang merupakan batik lokal yang dibuat dan dikembangkan oleh masyarakat Kabupaten Subang. Batik Subang memiliki perbedaan dengan batik lainnya, yaitu dalam segi motif, dimana motif batik Subang dominan menggambarkan kekayaan alam serta tradisi yang ada di Kabupaten Subang. Motif tersebut diantaranya motif sisingaan, nanas, bejana, wisma karya, dan biota laut.

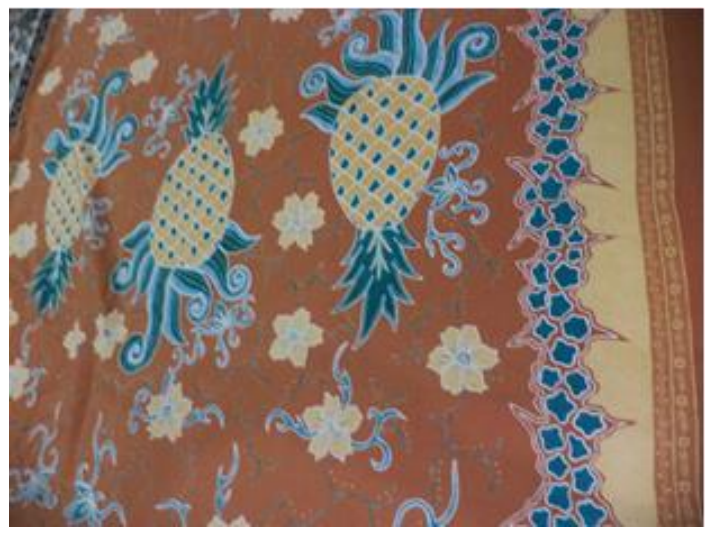

Gambar 1 Batik Subang

\subsection{Ganasan Batik}

Ganasan Batik merupakan salah satu industri pembuat batik khas Subang yang berada di kecamatan Binong, Kabupaten Subang. Di Ganasan Batik diproduksi beragam batik tulis dan cap dengan motif khas Subang.

Industri Batik Ganasan, selain menjual kain batik cap dan tulis, juga menjual berupa baju batik yang tersedia untuk pria dan wanita. Namun produk baju yang di produksi oleh Batik Ganasan masih minim, hal tersebut terkait dengan keinginan konsumen yang dominan memesan kain batik untuk dijadikan pakaian secara pribadi. Berikut rincian harga kain dan baju batik yang dijual oleh Batik Ganasan:
Tabel 1 Harga Kain dan Baju Batik

\begin{tabular}{l|l|l|l|l}
\hline & \multirow{2}{*}{ No } & Jenis & Harga & \multicolumn{2}{|l}{ Harga Baju Batik } \\
\cline { 4 - 5 }$\cdot$ & Batik & Kain Batik & Pria & \multirow{2}{*}{ Wanita } \\
\hline & & & & \\
\hline & & Rp. & Rp. & Rp. \\
1 & Batik & 90.000 & -185.000 & 350.000 \\
& Cap & Rp. & - Rp. & - Rp. \\
& & 250.000 & 450.000 & 450.000 \\
\hline & & Rp. & & \\
2 & Batik & $350.000-$ & - & - \\
& Tulis & Rp. & & - \\
& & 1.500 .000 & & \\
\hline
\end{tabular}

\subsection{Observasi}

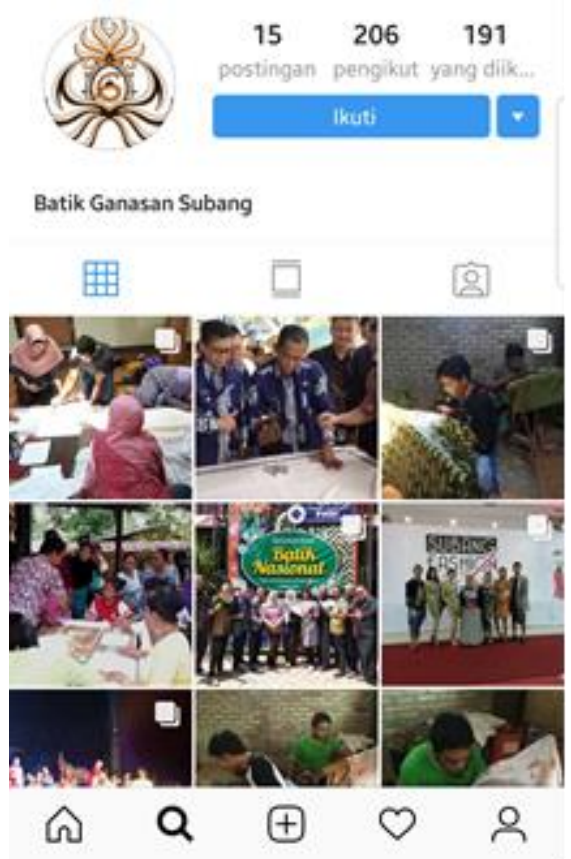

Gambar 2Observasi Media Sosial

Media sosial yang digunakan Batik Ganasan sebagai media promosi via daring adalah akun Instagram yang memiliki nama akun@mvlyana. Penggunaan media sosial Instagram kurang gencar terutama dalam hal mempromosikan produk Batik Ganasan. Tercatat, dari bulan mei 2014 hingga april 2019 hanya mengunggah postingan sebanyak 15 kali atau hanya mengunggah 3 postingan dalam kurun waktu satu tahun.

\subsection{Wawancara}

Menurut pemilik Batik Ganasan, Mulyana, industri ini mulai berdiri sejak 
tahun 2010 dan sudah menghasilkan beragam motif khas subang. Batik khas Subang yang diproduksi oleh Batik Ganasan ini memiliki perbedaan dengan batik khas Subang lainnya, dimana produk Batik Ganasan memiliki karakter motif yang berbeda serta memiliki keanekaragaman motif khas Subang, mulai dari Sisisngaan, Ganasa, pohon ki tambleg, biota laut pantura, gedung wisma karya, dan motif lainnya.

Namun selama sembilan tahun tersebut hingga saat ini, penjualan produk batik ganasan ternyata tidak mengalami penaikan, bahkan cenderung stagnan. Bahkan dengan sepinya penjualan batik, Mulyana terpaksa 'merumahkan' beberapa pegawai karena kurangnya permintaan batik. Karena, sejauh ini permintaan batik hanya ada dan di dominasi 90\% oleh pegawai negeri (PNS).

Terdapat beberapa faktor yang mempengaruhi sepinya permintaan, serta kurang minatnya masyarakat Kabupaten Subang terhadap Batik Ganasan. Faktor yang pertama adalah belum gencarnya promosi yang dilakukan, baik secara fisik ataupun secara digital (online)

\section{HASIL DAN PEMBAHASAN Strategi Perancangan}

Strategi perancangan terdiri dari dua kata yaitu strategi dan perancangan, yangmasing-masing kata mempunyai pengertian tersendiri. Strategi adalah cara yangditetapkan untuk mencapai sebuah tujuan. Sedangkan perancangan adalah suatuaktivitas pembuatan usulan-usulan yang merubah sesuatu yang telah ada menjadisesuatu yang lebih baik. Dari pengertian tersebut dapat diambil kesimpulan bahwastrategi perancangan adalah cara yang ditetapkan untuk membuat sesuatu yanglebih baik untuk mencapai tujuan.
Strategi perancangan yang dilakukan untuk membuat media promosi mengenai batik khas Subang yang efektif dan informatif yaitu:Membuat media video sebagai media utama untuk mempromosikan batik khas Subang. Serta, membuat media pendukung berupa brosur, katalog harga, x-banner, dan poster.

\section{Strategi Kreatif \\ Gaya Video Sinematik}

Cinematic Look atau gaya video sinematik adalah video yang memiliki kualitas visual yang tampilan hasil shot video mendekati kualitas gambar dari kamera dengan format film sinema atau bioskop, dan lebih memiliki kesan dramatis. Sehingga informasi mengenai kualitas dari Batik khas Subang lebih tersampaikan, terutama kepada target audience yang berusia 25 hingga 40 tahun.

\section{Aerial Video}

Aerial videografi adalah pengambilan video (shoot) dari udara, baik menggunakan pesawat, helicopter maupun helicam atau pesawat tanpa awak (UAV) atau yang populer dengan nama Drone.

Penggunaan aerial shot dapat memberikan kesan berbeda dibanding shot di darat, serta perspektif gambar yang dihasilkan dari aerial shot begitu kaya sehingga bisa mengambil shot dari berbagai sudut ketinggian. Penggunaan aerial shot dalam perancangan video promosi batik khas Subang yaitu sebagai visualisasi dari kekayaan dan keindahan alam di Kabupaten Subang yang berupa visualisasi daerah pegunungan dan pesisir pantai. 


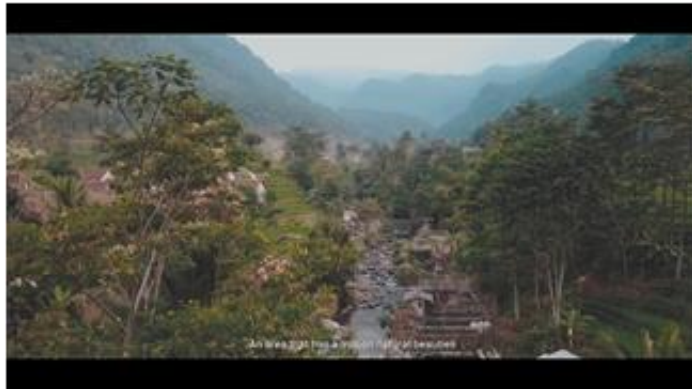

Gambar 3 Aerial Shot

\section{Tipografi}

Tipografi yang dipakai dalam perancangan video promosi batik khas Subang ini yaitu Sans serif atau tidak berkait. Nama dari font tersebut Roboto.

Pemilihan karakter font ini dikarenakan memiliki kesan simple dan mudah dibaca. Aplikasi font ini akan diterapkan pada penggunaan subtitle yang ada dalam video.

\section{AaBbCcDdEeFfGgHhli JjKkLIMmNnOoPpQqRr SsTtUuVvWwXxYyZz \\ poboto}

\section{Gambar 4 Font Roboto}

Pemilihan karakter font selanjutnya yaitu font bernama Vivaldi. Aplikasi dari font ini digunakan dalam headline dan judul media, termasuk penggunaan dalam intro video. Tujuan pemilihan karakter ini karena memiliki kesan indah dan anggun, sehingga dapat mempresentasikan dari karakter "Beauty of Subang".

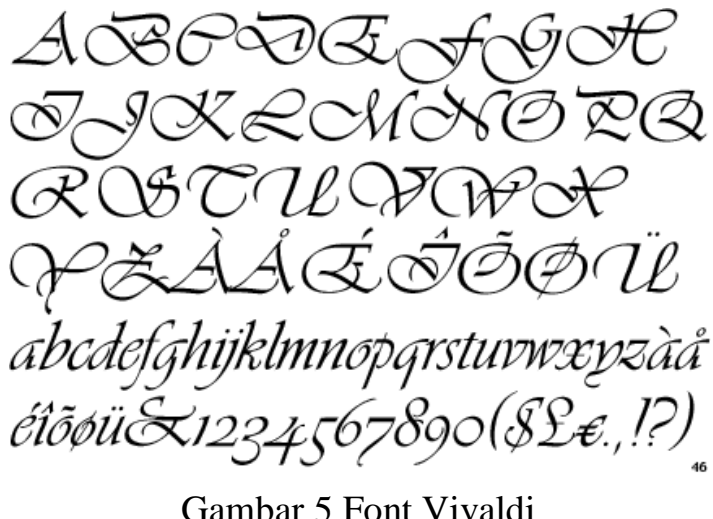

Pemilihan karakter font yang terakhir adalah Typo Grotesk. Font ini digunakan pada font isi media pendukung seperti brosur dan katalog. Pemilihan font ini karena memiliki tingkat keterbacaan yang tinggi sehingga mudah dibaca pada bentuk tulisan yang panjang atau paragraf.

\section{ABCDEFGHIJKLM NOPQRSTUWWXYZ abcdefghijklm nopqrstuvwXyz 0123456789!?\#}

Gambar 6 Font Typo Grotesk

\section{Implementasi Media}

Tone warna yang dipilih digunakan sebagai acuan warna yang akan dipakai pada pembuatan media pendukung, seperti poster, brosur dan katalog. Penentuan tone warna diambil dari warna yang terdapat pada logo Batik Ganasan. Terdapat juga warna lain yang digunakan sebagai warna pendukung.

Warna yang terdapat pada logo Batik Ganasan yaitu berwarna coklat. Warna coklat secara psikologi memberi kesan hangat dan nyaman. Selain itu warna coklat juga melambangkan kemodernan dan mahal, karena kedekatannya dengan warna emas.
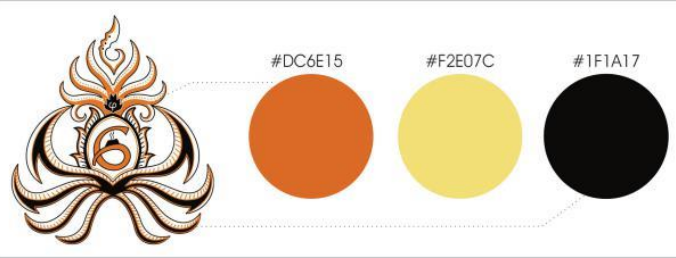

\section{Gambar 7 Tone Warna}

\section{Keyword}

Key Word berfungsi sebagai kata pembantu dalam sebuah pencarian data yang ingin didapatkan oleh target audiens. Key Word untuk video batik khas Subang ini adalah:
a. Video Batik
b. Batik Subang
c. Batik Ganasan 

d. Motif Batik Subang
e. The Beauty of Batik Subang

\section{Proses Produksi \\ Alat Produksi}

Tabel 2 Alat Alat Produksi

\begin{tabular}{c|l}
\hline Banyak & Alat \\
\hline 2 & Kamera DSLR \\
\hline 1 & Drone \\
\hline 1 & Lensa $85 \mathrm{~mm}$ \\
\hline 1 & Lensa 35mm \\
\hline 1 & Lensa 50mm \\
\hline 1 & Mikrofon \\
\hline 2 & Lampu Sorot \\
\hline 1 & $\begin{array}{l}\text { Reflektor } \\
\text { Cahaya }\end{array}$ \\
\hline 1 & Tripod \\
\hline 1 & Laptop \\
\hline
\end{tabular}

\section{Lokasi Pengambilan Gambar}

Lokasi pengambilan gambar dalam pembuatan video batik khas Subang dilakukan di beberapa lokasi yaitu Pegunungan Cisalak, Kebun Teh Jalancagak, Wisma Karya, Industri Batik Ganasan, Sungai Blanakan, dan Pantai Pondok Bali.

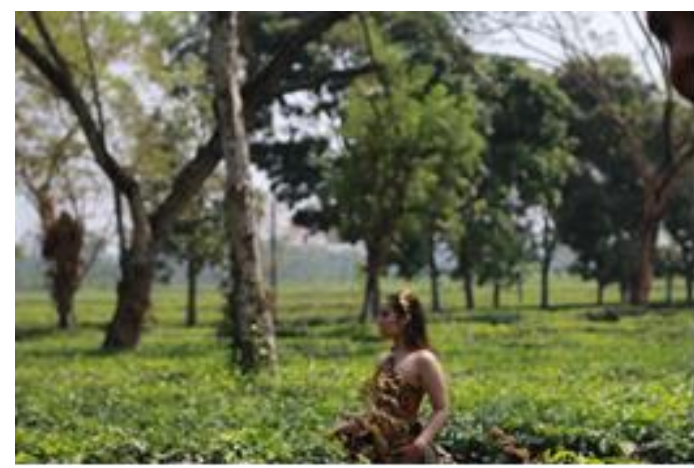

Gambar 8 Lokasi Pengambilan Gambar

\section{Storyboard}

Storyboard adalah suatu sketsa gambar yang disusun secara berurutan sesuai naskah cerita. Storyboard sendiri merupakan proses tahap lanjutan setelah membuat storyline, dimana rincian dari setiap shot video yang akan diambil, akan dijelaskan secara jelas dalam storyboard.

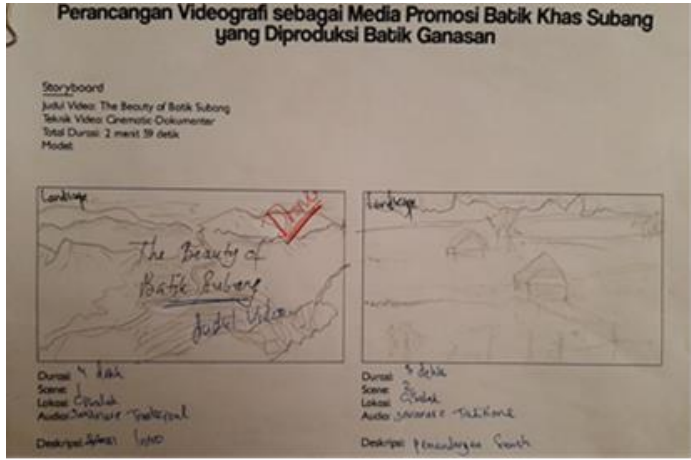

Gambar 9 Storyboard

\section{Pengambilan Gambar}

Pengambilan gambar dalam proses produksi video batik khas Subang berlangsung selama tiga hari yaitu pada tanggal 28, 29, dan 30 Juli 2019.

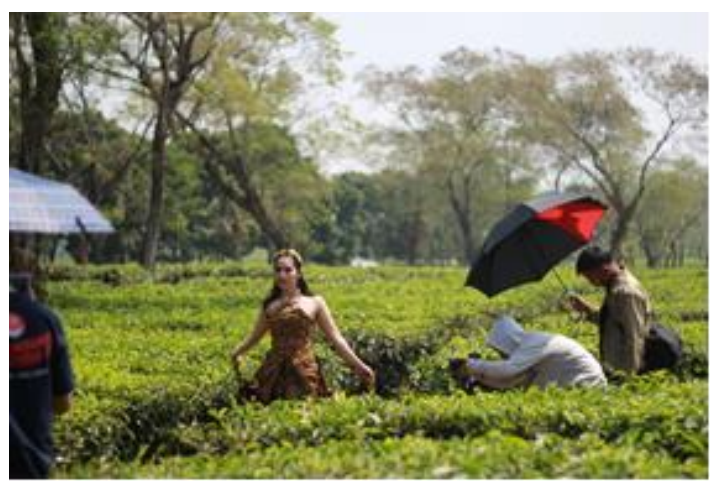

Gambar 10 Proses Pengambilan Gambar

\section{Editing}

Editing merupakan tahap terakhir dalam proses pembuatan video atau film. Pada proses ini hasil dari hasil produksi dilakukan pengeditan dan penggabungan file serta penambahan visual effect untuk menghasilkan hasil final yang siap untuk ditampilkan kepada masyarakat luas.Software yang dipakai dalam proses editing video promosi batik khas Subang ini yaitu Adobe Premiere Pro CC 2019, dengan resolusi video full HD (1920p x 1080p).

Beberapa tahap dalam proses editing video batik khas Subang diantaranya Penentuan Aspek Rasio, Penambahan Sinema Blackbar, Penyusunan Footage, Penambahan Subtitle, Penambahan Suara, Color Grading dan Rendering. 


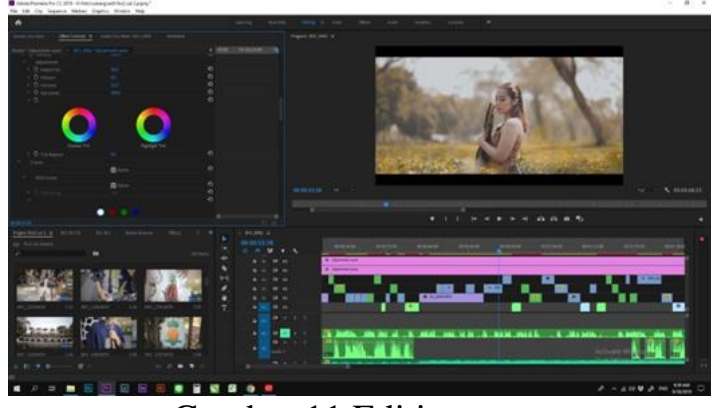

Gambar 11 Editing

\section{Strategi Distribusi}

Strategi distribusi berfungsi sebagai upaya penyaluran produk atau jasa ke tangan konsumen sesuai dengan target sasarannya untuk mendapatkan laba yang lebih besar.

Pendistribusian media utama dari promosi batik khas Subang yang berupa media video akan difokuskan pada penyebaran melalui media online yaitu melalui media sosial dengan menggunkana platform Youtube, Instagram dan Facebook.

Platform utama yang digunakan adalah Youtube, Youtube sendiri merupakan salah satu media sharing video terkemuka dan dengan menggukaan platform Youtube, video promosi akan lebih tersampaikan kepada target sasaran dan dengan cakupan yang luas. Akun Youtube yang akan digunakan yaitu akun milik Batik Ganasan yang bernama Batik Ganasan.
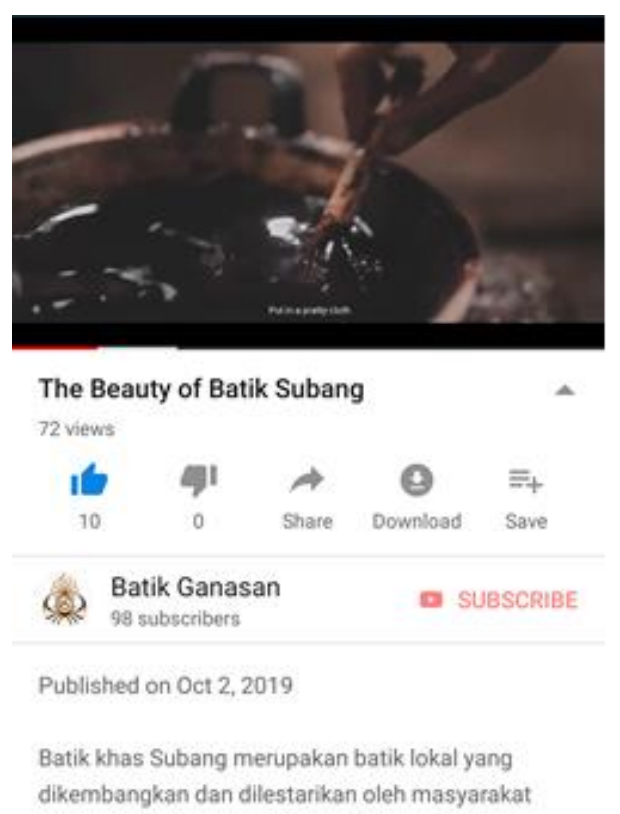

Gambar 12Youtube Batik Ganasan
Platform media sosial selanjutnya yang dipakai adalah Instagram. Instagram merupakan media sosial yang banyak digunakan, terutama oleh masyarakat Indonesia. Tercatat dalam situs Suara.com, sebanyak 56 juta atau 20,97\% dari total populasi masyarakat Indonesia merupakan pengguna aktif media sosial Instagram.Akun instagram yang digunakan adalah akun instagram industri Batik Ganasan yaitu @ batikganasan.official.Proses pengunggahan ke platform Instagram menggunakan fitur IGTV yang memiliki kelebihan dapat mengunggah video yang berdurasi lebih dari satu menit

Platform media sosial terakhir yang digunakan dalam penyebaran video promosi batik khas Subang adalah Facebook. Sama halnya seperti media sosial Instagram, yang bersumber dari Suara.com, pengguna Facebook di Indonesia sangat tinggi, menyentuh angka 120 juta pengguna atau $44,94 \%$ dari total populasi masyarakat Indonesia. Dan berdasarkan demografi pengguna, pengguna Facebook di Indonesia berada pada kalangan umur 18-34 tahun. Akun Facebook yang akan dipakai dalam proses penyebaran media promosi batik khas Subang ini adalah akun dari industri Batik Ganasan yaitu "Batik Ganasan Subang"

\section{Implementasi Media Video}

Media utama dalam promosi batik khas Subang ini yaitu video dengan gaya cinematic semi-dokumenter. Pada awal video terdapat sebuah intro yang diawali efek fade in atau animasi munculnya layar/stage video secara perlahan lalu diikuti dengan munculnya headline berupa judul video yaitu "The Beauty of Batik Subang" yang menggunakan font vivaldi. 


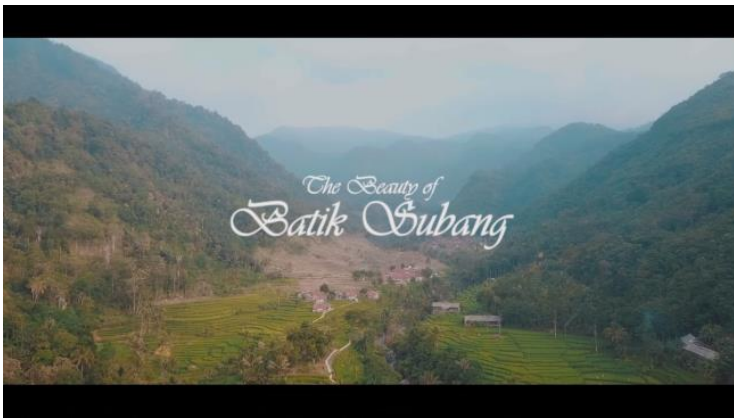

Gambar 13 Intro Video

Selanjutnya yaitu berupa penggambaran mengenai kekayaan alam Kabupaten Subang dan sekilas mengenai tradisi yang berkembang di Kabupaten Subang. dimana hal tersebut yang menjadi inspirasi motif batik khas Subang. Pemaparan video ini menggunakan voice over suara wanita dan diengkapi dengan subtitle berbahasa inggris. Subtitle bahasa inggris bertujuan agar video memiliki cakupan yang luas dan dapat dinikmati oleh audience diluar negara Indonesia.

Lokasi yang dipakai dalam scene ini yaitu area pegunungan dan pesawahan Cileat, Cisalak, area sungai pantai Cirewang, Legonkulon, Pantai Pondok Bali, dan Patung Sisingaan Wisma Karya, dan alat pengambilan gambar yang dipakai dalam scene video ini yaitu dominan menggunakan drone

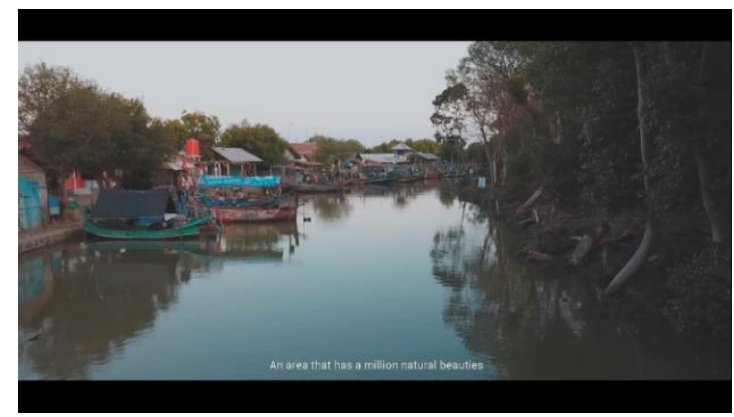

Gambar 14 Pemaparan Kekayaan Alam

Setelah pemaparan mengenai kekayaan alam dan tradisi yang ada di Kabupaten Subang yang menjadi inspirasi motif batik khas Subang, dilanjutkan dengan pemaparan proses pembuatan batik cap dan tulis yang berada di industri Batik Ganasan. Dalam scene ini menggunakan talent wanita agar keanggunan dan kualitas dari kain batik khas Subang terutama yang diproduksi oleh industri Batik Ganasan lebih tersampaikan. Dalam pemaparan voice over, disampaikan bahwa batik subang merupakan simbol identitas dan simbol keindahan Kabupaten Subang.

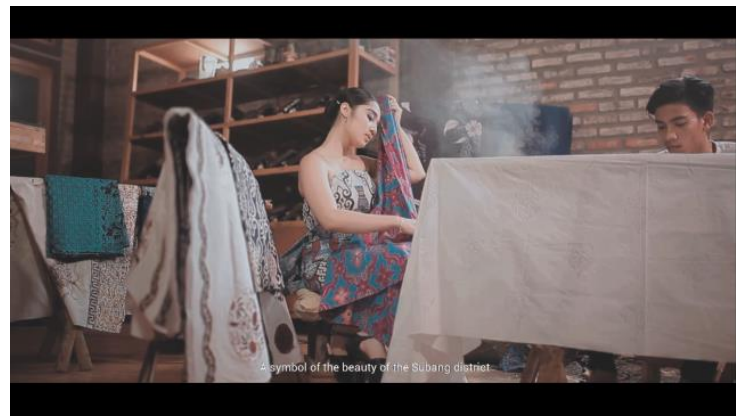

Gambar 15 Proses Pembuatan Batik

Selanjutnya yaitu pemaparan pernyataan dari pemilik industri Batik Ganasan mengenai filosofi motif batik khas Subang terutama yang diproduksi oleh industri batik Ganasan. Dimana, dalam isi pernyataannya menjelaskan bahwa kabupaten Subang memiliki kondisi geografis yang luas yaitu terdiri dari dataran tinggi, rendah dan pesisir pantai dan atas hal tersebut berkembanglah kekayaan serta tradisi di tiap wilayah di Kabupaten Subang yang menjadi isnpirasi terbentuknya motif.

Di industri Batik Ganasan sendiri beliau menjelaskan yang motif kain batik yang eksis dan paling banyak dicari yaitu tiga motif, motif Nanas, Sisingaan dan Bejana Purba.

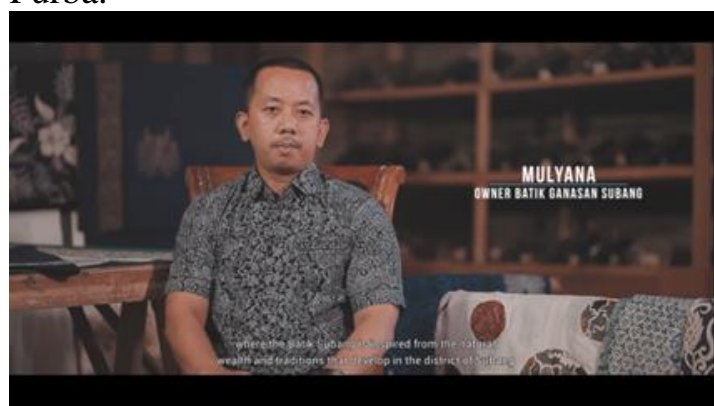

Gambar 16 Pemaparan Pemilik Industri Ganasan Batik

Setelah scene dari pemaparan dari pemilik industri Batik Ganasan, dilanjutkan dengan peragaan masing-masing motif batik 
yang diangkat yaitu motif nanas, sisingaan dan bejana purba dengen menggunakan talent yang berbeda.

Batik motif nanas diperagakan oleh talent wanita bernama Shany Dhayanti, lokasi dari peragaan batik ini yaitu di perkebunan teh Ciater, alasan memilih tempat tersebut karena mewakili kondisi geografis nanas yang tumbuh di daerah dataran tinggi sama halnya dengan perkebunan teh. Dalam pengambilan shot pada scene ini, selain menggunakan kamera DSLR juga menggunakan drone, agar menimbulkan kesan lebih dramatis.

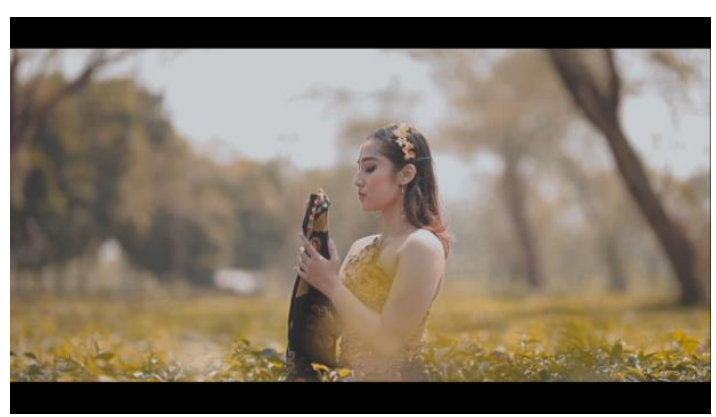

Gambar 17 Peragaan Kain Motif Nanas

Selanjutnya peragaan dari motif batik Sisingaan, peragaan ini dilakukan oleh talent pria bernama Rio Ramadhan yang bertujuan agar kesan dari motif Sisingaan yang cenderung gagah dan kuat dapat tersampaikan melalui model pria. Lokasi yang dipakai pada shot peragaan motif batik sisingaan yaitu di Wisma Karya Subang, tempat tersebut merupakan bangunan bersejarah bekas peninggalan masa penjajahan belanda yang secara filosofi dan sejarah sama dengan tradisi Sisingaan yang merupakan tradisi bentuk perlawanan terhadap penjajah Belanda pada masanya. Maka dipilihlah tempat Wisma Karya tersebut.

Terakhir adalah peragaan dari kain batik motif Bejana Purba, bejana purba merupakan benda purbakala yaitu berupa bejana perunggu terbesar yang ditemukan di daerah Serangpanjang, Subang. Peragaan motif batik ini dilakukan oleh talent wanita yang sama dengan peragaan motif nanas yaitu Shany Dhayanti. Lokasi pengambilan gambar dalam peragaan motif bejana purba ini yaitu di daerah pesawahan dan sungai Cileat, Cisalak, Subang. Pemilihan tempat ini dikarenakan, sejarah ditemukannya bejana puba yang berada di daerah dataran tinggi yaitu Serangpanjang dan dipilihlah lokasi yang sama berada di dataran tinggi yaitu di Cisalak. Selain itu untuk memperkenalkan juga bahwa di Kabupaten Subang memiliki keindahan alam berupa pesawahan, sungai dan area pegunungan Cisalak.

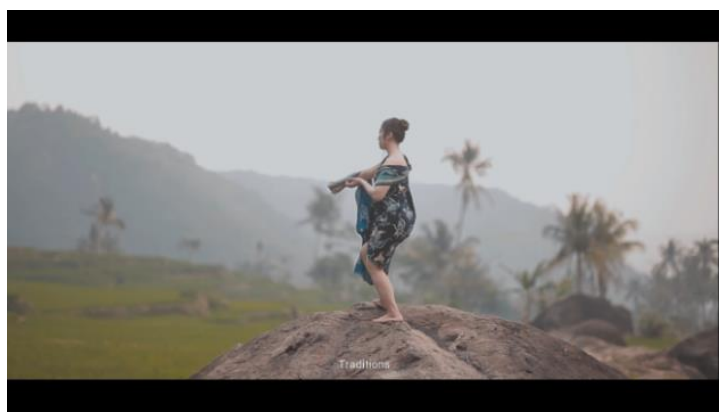

Gambar 18 Peragaan Kain Motif Bejana

\section{Media Pendukung}

Media pendukung yang digunakan untuk membantu proses promosi mengani batik khas Subang dan industri Batik Ganasan yaitu poster, katalog harga, dan brosur.

Poster merupakan salah satu media yang efektif untuk menyebarkan sebuah informasi sebuah produk atau jasa. Poster yang akan digunakan dalam promosi batik khas Subang ini yaitu poster digital yang akan disebarkan secara online melalui media sosial, yaitu platfom Facebook dan Instagram

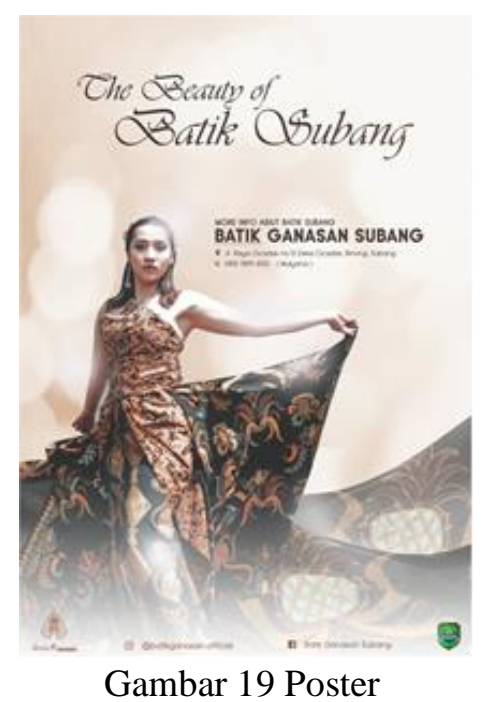


Brosur yang digunakan sebagai media pendukung promosi batik khas Subang dan industri Batik Ganasan adalah brosur yang berisi mengenai gambaran singkat mengenai sejarah batik subang dan filosofi batik.

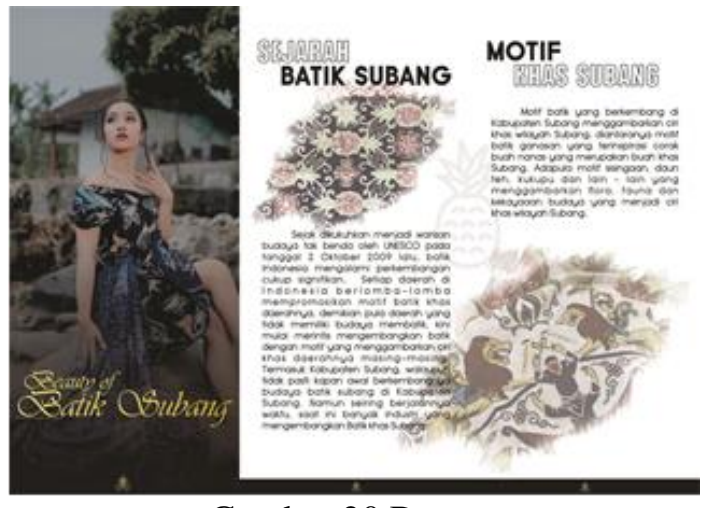

Gambar 20 Brosur

Katalog yang digunakan dalam proses penyebaran promosi batik khas Subang yaitu katalog harga yang berisi mengenai kumpulan harga dari kain batik tulis dan cap yang ada di industri Batik Ganasan. Dalam katalog harga tersebut berisi gambar tentang motif kain batik dengan kode yang berbeda pada setiap kain batik dan harga yang bervariasi.

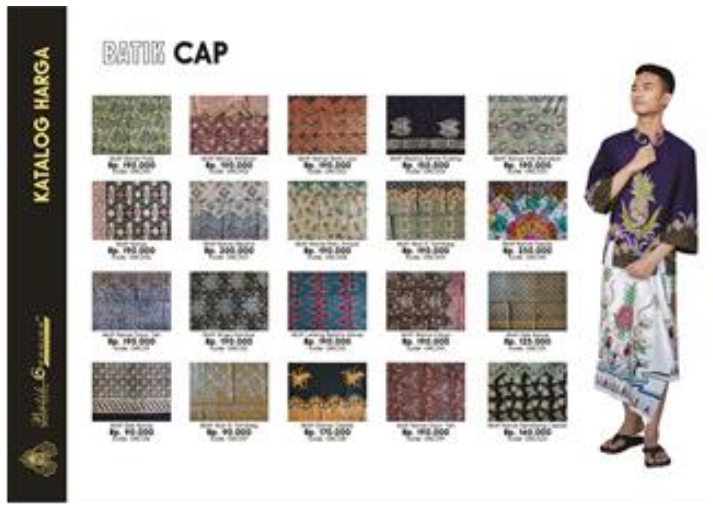

Gambar 21 Katalog Harga

\section{KESIMPULAN}

Batik khas Subang memiliki keunikan dibanding batik daerah lain terutama dalam aspek motif, dimana motif batik khas Subang menggambarkan kekayaan alam dan tradisi di Kabupaten Subang. Saat ini muncul banyak industri yang memproduksi batik khas Subang yang memiliki karakter batik beragam, industri batik tersebut diantaranya Batik Arves, Batik Kareumbi, dan Batik Ganasan.Atas hal tersebut, batik khas Subang berpotensi untuk terus dikenal bukan hanya oleh masyarakat Subang sendiri, tetapi dengan cakupan wilayah yang lebih luas. Berdasarkan hasil kuesioner yang disebar secara acak kepada masyarakat di Kabupaten Subang dan luar Kabupaten Subang, dihasilkan data bahwa lebih dari 70 persen responden menyukai konsep desain yaitu berupa komposisi warna dan penggambaran corak motif batik khas Subang dan tertarik untuk membeli produk batik khas Subang yang diproduksi oleh Batik Ganasan. Batik Ganasan sendiri adalah salah satu industri batik khas Subang yang menjadi wadah dan akses bagi calon konsumen untuk bisa mendapatkan batik khas Subang karena memiliki kelebihan dibanding industri batik khas Subang lainnya. Videografi adalah media yang tepat sebagai sarana promosi batik khas Subang untuk menggambarkan keunikan motif dan kualitas dari batik khas Subang yang diproduksi oleh Batik Ganasan. Penggunaan konsep video sinematik dengan sentuhan menggunakan aerial video, memberikan kesan dramatis dan informatif kepada target audience yaitu usia dewasa awal dengan rentang usia 25 hingga 40 tahun yang aktif menggunakan sosial media. Platform sosial media utama sebagai media promosi yang digunakan yaitu youtube juga memudahkan akses target audience untuk mendapatkan informasi mengenai batik khas Subang. Selain menggunakan media videografi, digunakan media lainnya yang berfungsi sebagaimedia pendukung promosi batik khas Subang yaitu melalui poster. 


\section{REFERENSI}

Anugerah, Ricky. (2016). Perancangan Video Promosi Taman

NasionalKarimunJawadenganTema "The

Beautiful Experience of KarimunJawa". Surabaya: InstitutTeknologiSepuluh November Assauri, Sofian. (2012). ManajemenPemasaran. Jakarta: Rajawali Pers. Asti, Musman\&Arini B, Ambar. (2011). WarisanAdiluhung Nusantara. Yogyakarta: ANDI.

Rusman, Kurniawan, D. \&Riyana, C. (2012).
PembelajaranBerbasisTeknologiInformasidanK omunikasiMengembangkanProfesionalitas

Guru. Jakarta: Raja Grafindo

$$
\text { Semedhi, Bambang. }
$$

Sinematografi-VideografiSuatuPengantar.

Bogor: Ghalia Indonesia

$$
\text { Susanto, Sewan }
$$

S.K. (1980).SeniKerajinan Batik Indonesia. Jakarta:DepartemenPerindustrianRepublik Indonesia.

Tjiptono, Fandy.

(2017). 